\title{
Prevalence of Obesity and Overweight and Its Associated Factors in Urban Adults from West Azerbaijan, Iran: The National Food and Nutritional Surveillance Program (NFNSP)
}

\author{
Bahareh Nikooyeh $^{1}$, Zahra Abdollahi ${ }^{2}$, Foroozan Salehi ${ }^{2}$, Sakineh Nourisaeidlou ${ }^{3}$, Majid Hajifaraji ${ }^{4}$, Maliheh Zahedirad ${ }^{1}$, Nastaran \\ Shariatzadeh $^{1}$, Ali Kalayi ${ }^{1}$, Fariba Babaei Balderlou ${ }^{5}$, Jafar Gholizadeh salmasi ${ }^{5}$, Rasool Entezarmahdi ${ }^{5}$, Zhila Ghorbannezhad ${ }^{5}$, Neda \\ Lotfollahi $^{1}$, Mohammad Maleki ${ }^{1}$, Tirang R. Neyestani ${ }^{1 *}$
}

1- Laboratory of Nutrition Research, National Nutrition and Food Technology Research Institute, Faculty of Nutrition Sciences and Food Technology, Shahid Beheshti University of Medical Sciences, Tehran, Iran

2- Nutrition Office, Iran Ministry of Health, Tehran, Iran

3- Food and Beverages Safety Research Center, Urmia University of Medical Sciences, Urmia, Iran

4- Department of Nutritional Policy-Making Research, National Nutrition and Food Technology Research Institute, Faculty of Nutrition Sciences and Food Technology, Shahid Beheshti University of Medical Sciences, Tehran, Iran

5- Deputy of Health, Urmia University of Medical Sciences, Urmia, Iran

Received: February 2016

Accepted: March 2016

\section{A B S T R A C T}

Background and Objectives: Globally, the prevalence of overweight/obesity is increasing at an alarming rate. According to the World Health Organization (WHO), about 1.9 billion adults worldwide are overweight, and of these, over 600 million are obese. The purpose of this study was to determine the prevalence of overweight and obesity in West Azerbaijan, Iran, in 2014.

Materials and Methods: Data were collected as part of the National Food and Nutritional Surveillance Program (NFNSP). A total of 249 men and women aged 20-60 from West Azerbaijan were included in the survey conducted in 2014. Body height and weight were measured with light clothing and no footwear after overnight fasting.

Results: Mean age of the participants was $38.5 \pm 7.8$ yrs. Mean BMI was $28.0 \pm 4.9 \mathrm{~kg} / \mathrm{m}^{2}$ (men: $26.8 \pm 4.2$ vs. women: 29.0 $\pm 5.3, \mathrm{p}<0.001$ ). The prevalence of overweight and obesity was $36.5 \%$ (men: $38.6 \%$ vs. women: $34.8 \%$, p: 0.439 ) and $33.3 \%$ (men: 25.4 vs. women: $40.0 \%$, p: 0.016 ), respectively. Women were more likely to be overweight or obese than males $(\mathrm{P}=0.038)$. Multiple logistic regression revealed that gender (women vs. men) (OR, 2.05; CI, 1.15-3.65; p,0.014) and age (OR, 1.06; CI, 1.01-1.1; p,0.004) increased the risk of becoming overweight or obese. Women who were housewives were five times more at risk of becoming overweight or obese (OR: 4.93; CI: 1.9-12.3; $\mathrm{p}<0.001$ ) even after adjusting for age and educational level.

Conclusions: The high prevalence of weight problems in West Azerbaijan is a serious health concern, especially in women. The lifestyle of housewives is a potential risk factor for weight gain in women.

Keywords: Obesity, Prevalence, Azerbaijan, Adults

\section{Introduction}

Obesity is often defined as a condition of excessive fat accumulation in the body to such an extent that health may be impaired (1). Globally, the prevalence of overweight/obesity is increasing at an alarming rate. Based on a systematic analysis of global trends in body mass index (BMI) in adults, the mean BMI increased by $0.4-0.5 \mathrm{~kg} / \mathrm{m}^{2}$ per decade between 1980 and 2008 (2). According to the World Health Organization (WHO), about 1.9 billion adults worldwide are overweight, and of these, over 600 million are obese (3). It has been estimated that obesity accounts for 3.4 million deaths annually and 93.6 million disability-adjusted life years (DALYs) in 2010 (4).

Based on recent reports, the prevalence of obesity has increased by approximately three times in the developing countries during the last two decades primarily as a result of lifestyle changes including 
decreased physical activity and excessive intake of high energy foods (5). Iran has been no exception. According to the recent WHO report, more than 50\% of the Iranian adult population are overweight or obese (4).

Obesity is a chronic disease per se (1) and a wellknown risk factor for other non-communicable diseases (NCDs). Overweight or obese people are at an increased risk of coronary heart disease, type 2 diabetes, cancers (endometrial, breast and colon), hypertension, dyslipidaemia, stroke, sleep apnea, respiratory problems and osteoarthritis (6-7). Moreover, excessive body weight can influence quality of life, education, capacity of work and reproductive performance (8-9). According to the recommendations of WHO, BMI is used as a screening tool for overweight or obesity (1) so that BMI $\geq 25$ is often accompanied by a higher risk of health problems and premature death (1). This cutoff, however, has been revised for Asian populations (10).

The purpose of this study was to determine the prevalence of overweight and obesity and some selected determinants of it in the urban population of West Azerbaijan, Iran.

\section{Materials and Methods}

Data were collected as a part of the National Food and Nutritional Surveillance Program (NFNSP, www.nfns.ir), which is an ongoing population-based survey conducted periodically in Iran by the National Nutrition and Food Technology Research Institute (NNFTRI) with the assistance of the United Nations Children's Fund (UNICEF) and Nutrition Office of the Deputy of Health of Iran Ministry of Health $(\mathrm{MOH})$ to assess the nutrition status of a large representative sample of the Iran population.

Sample size: Based on the prevalence of overweight and obesity in men (49.4\% and $13.6 \%$, respectively) and women (64.3\% and $29.3 \%$, respectively) of the adjacent province population (11), with the precision of $7 \%$ and prevalence of $50 \%$, at least 195 subjects were needed to estimate the prevalence. A total of 249 urban men and women (aged 20-60 yrs) from Urmia city, center of West Azerbaijan province, were included in the survey conducted in 2014.

Population sampling: Following coordination with the Provincial Deputy of Health of West Azerbaijan, households, as data units, from Urmia city were randomly selected. To do this, Urmia city was divided to 5 geographical regions (north, south, east, west and center). From each region, 50 households were randomly selected from their home telephone numbers. Selected families were contacted by call to describe the aims of the study and to see if they are willing to participate. Assessments were done either at the urban health centers or at the household residence, just in case. A written informed consent was signed by all participants prior to the study. The Ethics Committee of NNFTRI approved the National Food and Nutritional Surveillance Program (NFNSP).

Anthropometrics: Body height and weight were measured with light clothing and no footwear after an overnight fasting. Height was measured in a standing position using a fixed stadiometer to the nearest of 0.1 $\mathrm{cm}$. Weight was measured to the nearest of $0.1 \mathrm{~kg}$. BMI was calculated as weight in kilograms divided by the square of height in meters $\left(\mathrm{kg} / \mathrm{m}^{2}\right)$.

In the present study, two sets of BMI categorization were used: Set 1, which was our main categorization: underweight, BMI $<18.5 \mathrm{~kg} / \mathrm{m}^{2}$; normal weight, BMI: 18.5 - $24.9 \mathrm{~kg} / \mathrm{m}^{2}$; overweight, BMI: $25-29.9$ $\mathrm{kg} / \mathrm{m}^{2}$; and obese, BMI $\geq 30 \mathrm{~kg} / \mathrm{m}^{2}$ (1). Set 2 , which is suggested for Asians: underweight, BMI < 18.5 $\mathrm{kg} / \mathrm{m}^{2}$; increasing but acceptable risk, which was considered as normal weight, BMI: $18.5-23 \mathrm{~kg} / \mathrm{m}^{2}$; increased risk, which was considered as overweight, $23-27.5 \mathrm{~kg} / \mathrm{m}^{2}$; and high risk or obese, BMI $\geq 27.5$ $\mathrm{kg} / \mathrm{m}^{2}(10)$.

The demographic variables used for the analyses included: sex, age groups (20-30, 30-40, 40-50, 50-60 years), educational level (illiterate, high school, university study), and marital status.

Statistical analyses: All statistical analyses were performed using the Statistical Package for Social Sciences (SPSS version 21; SPSS Inc, Chicago, IL). Mean and standard deviation (mean \pm SD) was determined for quantitative variables. Frequency and proportion was calculated for the categorical variables. Chi-square was applied to determine the association between categorical variables. The between-group differences were evaluated by student's t-test and analysis of variance (ANOVA). Pearson's $r$ and Spearman's coefficients were used to describe the strength of relationship for normal and non-normal variables, respectively. The logistic 
regression model was performed to evaluate the association of the demographic variables with obesity so that BMI was dichotomized into the overweight/obese categories (BMI $\geq 25 \mathrm{~kg} / \mathrm{m}^{2}$ ). In this study, $\mathrm{p}$ value less than 0.05 was considered as statistically significant (two-tailed).

\section{Results}

Descriptive characteristics of the participants are presented in Table 1. Mean age was $38.5 \pm 7.8$ yrs, ranging between 20 and 60 yrs. About half of the subjects were females. The majority of the participants had secondary education $(65.5 \%)$, and were married $(96.4 \%)$.

Table 1. Participan's characteristics

\begin{tabular}{|c|c|}
\hline Age group & $\mathrm{n}(\%)$ \\
\hline $20-30 \mathrm{yr}$ & $38(15.3)$ \\
\hline $30-40$ & $117(47.0)$ \\
\hline $40-50$ & 77 (30.9) \\
\hline $50-60$ & $17(6.8)$ \\
\hline \multicolumn{2}{|l|}{ Sex } \\
\hline Men & $114(45.8)$ \\
\hline Women & $135(54.2)$ \\
\hline \multicolumn{2}{|l|}{ Education } \\
\hline illiterate & $16(6.4)$ \\
\hline High school & $163(65.5)$ \\
\hline University study & $70(28.1)$ \\
\hline \multicolumn{2}{|l|}{ Family status } \\
\hline Married & $240(96.4)$ \\
\hline Job & $9(3.6)$ \\
\hline Official employee & $37(32.5)$ \\
\hline Free lancer & $77(67.5)$ \\
\hline Women Employee & $29(21.5)$ \\
\hline Housewife & $106(78.5)$ \\
\hline
\end{tabular}

Table 2 shows the anthropometric measures by gender. Mean BMI was $28.0 \pm 4.9 \mathrm{~kg} / \mathrm{m}^{2}$ (men: $26.8 \pm 4.2$ vs. women: $\left.29.0 \pm 5.3 \mathrm{~kg} / \mathrm{m}^{2}, \mathrm{p}<0.001\right)$. Table 3 shows the prevalence for the BMI categories by gender, age groups, education status and job in the participants. None of the subjects were underweight.

The prevalence of overweight and obesity, based on Set 1 categorization, was $36.5 \%$ (38.6\% in males vs. $34.8 \%$ in females, $\mathrm{p}=0.439)$ and $33.3 \%(25.4 \%$ in males vs. $40.0 \%$ in females, $\mathrm{p}=0.016$ ), respectively (Table 3). However, when Set 2 categorization was applied, the prevalence of overweight decreased to $31.7 \%$ (males, $34.2 \%$ vs. females, $29.6 \%$, $\mathrm{p}=0.021$ ) while that of obesity increased to $52.2 \%$ (males, $43.9 \%$ vs. females, $59.3 \%, \mathrm{p}=0.021$ ). Women were more likely to be obese than males with both categorizations $(\mathrm{p}=0.038)$.

Among the women, the prevalence of overweight and obesity varied by job, with the highest rate in housewives. However, there were no significant differences in the distribution of weight problems among the age groups or education status. Multiple logistic regression revealed that gender (women vs. men) (OR, 2.05; CI, 1.15-3.65; p=0.014) and age (OR, 1.06; CI, 1.01-1.1; $\mathrm{p}=0.004)$ increased the risk of becoming overweight or obese. Women who were housewives were five times more at risk of becoming overweight or obese (OR: 4.93; CI: 1.9-12.3; $\mathrm{p}<0.001)$ after adjusting for age. The prevalence of overweight and obesity decreased with educational level in women but not in men. After adjusting for age, women with an educational level of college or above had the lowest odds of being overweight/obese $(\mathrm{OR}=2.6 ; \mathrm{CI}=1.0-6.2, \mathrm{p}=0.03)$ or obese $(\mathrm{OR}=0.47)$ compared to those with an educational level lower than high school. When job was applied into the model, the effect of education disappeared, and the risk of being overweight/obese for housewives increased by six times $(\mathrm{p}=0.009)$.

Table 2. Mean anthropometric measures of the participants by gender

\begin{tabular}{lcccc}
\hline Variable & \multicolumn{2}{c}{ Gender } & p value & Total \\
\cline { 2 - 4 } & Men & Women & & \\
\hline Height $(\mathrm{cm})$ & $173.8 \pm 6.7$ & $159.1 \pm 5.5$ & $<0.001^{*}$ & $165.9 \pm 9.5$ \\
Weight $(\mathrm{kg})$ & $81.2 \pm 13.9$ & $73.6 \pm 13.3$ & $<0.001^{*}$ & $77.1 \pm 14.1$ \\
BMI $\left(\mathrm{kg} / \mathrm{m}^{2}\right)$ & $26.8 \pm 4.2$ & $29.0 \pm 5.3$ & $<0.001^{*}$ & $28.0 \pm 4.9$ \\
\hline
\end{tabular}

*p value $<0.05$, differences were determined by student's $\mathrm{t}$-test. 
Bahareh Nikooyeh, et al: obesity in adults from Azarbaijan

Table 3. Distribution of BMI status by gender, age groups, education, and job

\begin{tabular}{|c|c|c|c|c|c|}
\hline Variable & & $\begin{array}{c}\text { Normal } \\
\mathrm{n}(\%)\end{array}$ & $\begin{array}{c}\text { Overweight } \\
\mathrm{n}(\%)\end{array}$ & $\begin{array}{c}\text { Obese } \\
\mathrm{n}(\%)\end{array}$ & $\mathrm{p}$ value \\
\hline Gender & $\begin{array}{l}\text { Men } \\
\text { Women }\end{array}$ & $\begin{array}{l}41(36.0) \\
34(25.2)\end{array}$ & $\begin{array}{l}44(38.6) \\
47(34.8)\end{array}$ & $\begin{array}{l}29(25.4) \\
54(40.0)\end{array}$ & $0.038^{*}$ \\
\hline Age group & $\begin{array}{l}20-30 \\
30-40 \\
40-50 \\
50-60\end{array}$ & $\begin{array}{c}15(39.5) \\
39(33.3) \\
15(19.5) \\
6(35.3)\end{array}$ & $\begin{array}{c}12(31.6) \\
42(35.9) \\
32(41.6) \\
5(29.4)\end{array}$ & $\begin{array}{c}11(28.9) \\
36(30.8) \\
30(39.0) \\
6(35.3)\end{array}$ & 0.341 \\
\hline Education & $\begin{array}{l}\text { illiterate } \\
\text { High school } \\
\text { University study }\end{array}$ & $\begin{array}{c}4(25.0) \\
45(27.6) \\
26(37.1)\end{array}$ & $\begin{array}{c}3(18.8) \\
62(38.0) \\
26(37.1)\end{array}$ & $\begin{array}{c}9(56.3) \\
56(34.4) \\
18(25.7)\end{array}$ & 0.141 \\
\hline \multicolumn{6}{|l|}{ Job } \\
\hline Men & $\begin{array}{l}\text { Official employee } \\
\text { Free lancer }\end{array}$ & $\begin{array}{l}15(40.5) \\
26(33.8)\end{array}$ & $\begin{array}{l}13(35.1) \\
31(40.3)\end{array}$ & $\begin{array}{c}9(24.3) \\
20(26.0)\end{array}$ & 0.773 \\
\hline Women & $\begin{array}{l}\text { Employee } \\
\text { Housewives }\end{array}$ & $\begin{array}{l}15(51.7) \\
19(17.9)\end{array}$ & $\begin{array}{c}5(17.2) \\
42(39.6)\end{array}$ & $\begin{array}{c}9(31.0) \\
45(42.5)\end{array}$ & $0.001^{*}$ \\
\hline
\end{tabular}

*p value $<0.05$, differences were determined by Chi square test.

\section{Disc ussion}

There was a very high prevalence $(\sim 70 \%)$ of overweight/obesity in our subjects, and women were more affected. Using BMI categorization for Asians (10), the prevalence of overweigh/obesity even increased to about $84 \%$, with over half of the population considered as obese. This finding is comparable with the reported prevalence rates of about $78 \%$ in the east Azerbaijan (11) and 59\% in Ardabil (12), both adjacent to Urmia. Similar numbers have been reported from Semnan ( 67\%) (13), and relatively lower prevalence from the 20-70 yr population of the north of Iran (53.6\%) (14). In the first nationwide survey of the prevalence of weight abnormalities in the 15-65 yr population of Iran, the prevalence of overweight/obesity (BMI $\geq 25 \mathrm{~kg} / \mathrm{m}^{2}$ ) was $42.8 \%$ in men and $57 \%$ in women (15).

In the present work, there was an adverse association between the BMI and educational level of women, a finding that has already been reported from both the northern (16) and southern (17) provinces of Iran. However, we found that being a housewife could override the protective effect of educational level and pose a remarkable (5-6 times higher) risk of being overweight/obese. Determinants of these higher than average rates of overweight/obesity in the north-west provinces of Iran deserve more studies.

In recent decades, along with the improvement of living standards, weight gain has become a prominent public health concern all around the world. The transition from a traditional to Western diet and remarkable declines in physical activity could be the main reasons of the escalating rates of overweight and obesity in the developing countries (18). Today, the intake of a diet high in saturated fats and sugar is increasing, while consumption of fruits and vegetables remains usually inadequate. These poor quality diets are associated with high prevalence of weight problems and the related pathologies (19)

Dissimilar to the studies in China (20) and Japan (21), we found that women had a higher risk for developing obesity than men. However, the association between obesity and gender observed in our study is in accordance with other provincial and national studies (13-15) and consistent with the findings from studies carried out in some other countries $(13-14,22)$. The majority of studies have reported higher prevalence of weight gain in women than in men (22-23). A study from Iran reported that the percentage of obese women was about $10-15 \%$ higher than obese men at the same age specific group (24). Physical activity pattern and more importantly dietary habits may contribute to this gender difference. Educational level (16), socio-economic status (25), number of pregnancies, and the amount of weight gain in each pregnancy in women (26) could be other contributing factors. 
Worthy of note, the present study showed the association between the prevalence of overweight and obesity and educational level in women but not in men, even after adjustment for age. Similar findings were found in another study (27). It is possible that high-educated women are more aware of the adverse effect of weight gain on health (28). In another study from Iran, BMI was negatively associated with educational level in women but, unlike our findings, educational level was directly associated with BMI in men (16)

We found housewives at tremendously higher risk for developing obesity, and this association remained significant even after adjustment for age and educational level. Studies of association between job and women weight gain were carried out in some countries (29-30). It has been suggested that housewives have lower opportunities for physical activity and, on the other side, may have irregular eating patterns due to typical homemaking duties (30). In the current study, lack of physical activity and food consumption data are among the limitations.

Obesity is a complex, multifactorial disease that requires long-term approaches for effective prevention and management (1). It is a population problem rather than just a disorder of individual behavior. Recent hypotheses suggest although diet and exercise are the main determinants of weight and social factors (including fast food intake, high costs of healthy foods, and lack of access to safe places to play and exercise) play important roles in the high prevalence of obesity by reducing the likelihood of healthy eating and active living behaviors (5-7). It is suggested that health interventions to control obesity should not just target obese individuals; rather the awareness of the whole community about the adverse effects of increased body fat mass must be refreshed every day. Moreover, an integrated approach,

\section{References}

1. Organization WH. Obesity: Preventing and managing the global epidemic: World Health Organization; 2000.

2. Finucane MM, Stevens GA, Cowan MJ, Danaei G, Lin JK, Paciorek CJ, et al. National, regional, and global trends in body-mass index since 1980: Systematic analysis of health examination surveys and involving actions in all sectors of society, is required in order to shift the BMI distribution to a favorable direction $(1,31)$. According to the WHO reports on non-communicable diseases to achieve optimal health, the median BMI for adult populations should be in the range of $21-23 \mathrm{~kg} / \mathrm{m}^{2}$, while the goal for individuals should be to maintain a BMI in the range $18.5-24.9 \mathrm{~kg} / \mathrm{m}^{2}$ (4).

This study had some limitations. With a crosssectional design, it is not possible to attribute causality. Our sample size was rather small. Social determinants of weight gain in Iranians warrant further studies.

\section{Conclusions}

In conclusion, the high prevalence of weight problems in the urban population of Urmia, West Azerbaijan, especially in women, is a serious health concern. By using the suggested BMI cut-offs for Asians, the prevalence rate of overweight/obesity would rise remarkably. The lifestyle of housewives is a potential risk factor for weight gain in women. Our results call for urgent action to aware the people of the importance of healthy life style, including dietary pattern modifications and active living behaviors. There is a need for effective preventive and educational strategies against obesity. Undoubtedly, further interventional studies are needed.

\section{Financial disclosure}

The authors declared no financial interest.

\section{Funding/Support}

The National Food and Nutrition Surveillance (NFNS) is financially supported by UNICEF, Community Nutrition Office of Iran Ministry of Health, and NNFTRI. All laboratory bench works were performed at the Laboratory of Nutrition Research, NNFTTRI. We wish to thank the participants for taking part in this project.

epidemiological studies with 960 country-years and 9.1 million participants. The Lancet. 2011;377(9765):557-67.

3. Obesity and overweight [database on the Internet] 2014. Available from: http://www.who.int/mediacentre/ factsheets/fs311/en/.

4. Alwan A. Global status report on noncommunicable diseases 2010: World Health Organization; 2011. 
5. Hossain P, Kawar B, El Nahas M. Obesity and diabetes in the developing world-a growing challenge. New England Journal of Medicine. 2007;356(3):213-5.

6. Bray GA. Medical consequences of obesity. The Journal of Clinical Endocrinology \& Metabolism. 2004;89(6):2583-9.

7. Finer N. Medical consequences of obesity. Medicine. 2015;43(2):88-93.

8. Kolotkin R, Meter K, Williams G. Quality of life and obesity. Obesity Reviews. 2001;2(4):219-29.

9. McLaren L. Socioeconomic status and obesity. Epidemiologic Reviews. 2007;29(1):29-48.

10. WHO Expert Consultation. Appropriate body-mass index for Asian populations and its implications for policy and intervention strategies. Lancet. 2004 Jan 10;363(9403):157-63.

11. Seyffarshad M, Kousha A, Pourdowlati S, Karamouz M, Farahbakhsh M, Hakimi S. Cardiac risk factor analysis in East Azerbaijan, Iran. The Cardiology. 2007;3(1):1-4.

12. Sadeghi-Bazargani H, Jafarzadeh H, Fallah M, Hekmat S, Bashiri J, Hosseingolizadeh G, et al. Risk factor investigation for cardiovascular health through WHO STEPS approach in Ardabil, Iran. Vasc Health Risk Manag. 2011;7:417-24.

13. Rashidy-Pour A, Malek M, Eskandarian R, Ghorbani R. Obesity in the Iranian population. Obes Rev. 2009 Jan;10(1):2-6.

14. Hajian-Tilaki KO, Heidari B. Prevalence of obesity, central obesity and the associated factors in urban population aged 20-70 years, in the north of Iran: A population-based study and regression approach. Obes Rev. 2007 Jan; 8(1):3-10.

15. Janghorbani M, Amini M, Willett WC, Mehdi Gouya M, Delavari A, Alikhani S, et al. First nationwide survey of prevalence of overweight, underweight, and abdominal obesity in Iranian adults. Obesity (Silver Spring). 2007 Nov;15(11):2797-808.

16. Maddah M, Eshraghian MR, Djazayery A, Mirdamadi R. Association of body mass index with educational level in Iranian men and women. Eur J Clin Nutr. 2003 Jul;57(7):819-23.

17. Amani R. Comparison between bioelectrical impedance analysis and body mass index methods in determination of obesity prevalence in Ahvazi women. Eur J Clin Nutr. 2007 Apr;61(4):478-82.

18. Popkin BM, Adair LS, Ng SW. Global nutrition transition and the pandemic of obesity in developing countries. Nutrition Reviews. 2012;70(1):3-21.
19. Popkin BM. The nutrition transition and its health implications in lower-income countries. Public Health Nutrition. 1998;1(01):5-21.

20. Wang K, Wang D, Pan L, Yu Y, Dong F, Li L, et al. Prevalence of Obesity and Related Factors among Bouyei and Han Peoples in Guizhou Province, Southwest China. PloS one. 2015;10(6):e0129230.

21. Aoyagi K, Kusano Y, Takamura N, Abe Y, Osaki M, Une H. Obesity and cardiovascular risk factors among men and women aged 40 years and older in a rural area of Japan. Journal of Physiological Anthropology. 2006;25(6):371-5.

22. Garawi F, Devries K, Thorogood N, Uauy R. Global differences between women and men in the prevalence of obesity: is there an association with gender inequality\&quest. European Journal of Clinical Nutrition. 2014;68(10):1101-6.

23. La Rosa E, Valensi P, Cohen R, Soufi K, Robache C, Le Clesiau H. [Socioeconomic determinism of obesity in the Seine-Saint-Denis area]. Presse Medicale (Paris, France: 1983). 2003;32(2):55-60.

24. Bahrami H, Sadatsafavi M, Pourshams A, Kamangar F, Nouraei M, Semnani S, et al. Obesity and hypertension in an Iranian cohort study: Iranian women experience higher rates of obesity and hypertension than American women. BMC Public Health. 2006;6(1):158.

25. Maddah M. Overweight and obesity among Iranian female adolescents in Rasht: More overweight in the lower social group. Public Health Nutr. 2007 May; 10(5):450-3.

26. Maddah M, Nikooyeh B. Urban and rural differences in pregnancy weight gain in Guilan, northern Iran. Matern Child Health J. 2008 Nov;12(6):783-6.

27. Cai L, Han X, Qi Z, Li Z, Zhang Y, Wang P, et al. Prevalence of Overweight and Obesity and Weight Loss Practice among Beijing Adults, 2011. 2014; PLoS ONE 9(9): e98744

28. Wu Y, Huxley R, Li M, Ma J. The growing burden of overweight and obesity in contemporary China. CVD Prevention and Control. 2009;4(1):19-26.

29. Caban AJ, Lee DJ, Fleming LE, Gómez-Marín O, LeBlanc W, Pitman T. Obesity in US workers: The national health interview survey, 1986 to 2002. American Journal of Public Health. 2005;95(9):1614.

30. Ersoy C, Imamoglu S. Comparison of the obesity risk and related factors in employed and unemployed (housewife) premenopausal urban women. Diabetes Research and Clinical Practice. 2006;72(2):190-6.

31. Rose G, Day S. The population mean predicts the number of deviant individuals. BMJ. 1990;301(6759):1031-4. 